\title{
THE IMPORTANCE OF VEGETABLE PROCESSING AUTOMATIZATION USING THE EXAMPLE OF POTATO ABRASION PEELING
}

\author{
András Palkovics \\ Faculty of Horticulture and Rural Development, John von Neumann University, Hungary \\ https://doi.org/10.47833/2020.2.AGR.020
}

\begin{tabular}{|c|c|}
\hline $\begin{array}{l}\text { Keyword } \\
\text { vegetable } \\
\text { potato pee } \\
\text { abrasion p }\end{array}$ & essing \\
\hline Article hi & \\
\hline $\begin{array}{l}\text { Received } \\
\text { Revised }\end{array}$ & $\begin{array}{l}10 \text { Feb } 2020 \\
13 \text { March } 2020\end{array}$ \\
\hline Accepted & 20 March 2020 \\
\hline
\end{tabular}

\begin{abstract}
Potato (Solanum tuberosum L.) is one of the most important agricultural crops suitable for human consumption. High amount of valueless by-product is produced during the processing of potato peeling. Depending on the type of the abrasive peeling machine the by-product can be $15-40 \%$ of the unpeeled raw material. The purpose of the recent paper is to show that the peel losses can be decreased with a modern automation. This research is illustrated by a vegetable processing manufacture still operating.
\end{abstract}

\section{Introduction}

The purpose of peeling is to remove the skin tissue (peel) of raw fruits and vegetables; enhancing the appearance and taste of the finished product; achieving a clean, peeled surface, while minimizing peel losses [1]. Food industry applies the method of peeling in the case of potatoes, roots, tubers, and fruits. There are several methods of peeling: mechanical peeling (knife peeling, abrasion peeling); peeling in a moist and warm medium (water, condensed water, alkaline solution); heating the peel by drying; carbonising or burning the peel; freezing and thawing of the vegetable surface. Removal of inedible or undesirable parts of fruits and vegetables (e.g. leeks, artichokes) is called end cutting [2].

\section{Material and method}

Research was carried out at the vegetable processing plant of St. Andrew's Ltd., Kunpeszér. This plant has been cleaning and processing various vegetable plants with an automated production line for many years. We tested Hungarian Desiree potato, $50 \mathrm{~kg}$ per each machine filling.

For the research we used a "ROPAI 1000" (Fig. 1.) abrasive peeling machine. This machine was manufactured by BanhiDesign s.r.o. (SK), and developed by Dolansgate Ltd. (Cy) into a professionally automated version through a Delta PLC system. Water consumption was tested with a certified water meter.

Desiree potato is one of the most popular potato varieties. It has a medium, late vegetation period. The tubers are characterized by a pink shell, a light yellow flesh, a large oval shape with middle-sit buds. It produces large volumes, the number of tubers is average. Desiree potato remains firm after cooking. It is classified as cooking type B, multipurpose variety, excellent for fries. It has a medium dry matter content.

\footnotetext{
* Corresponding author. E-mail address: palkovics.andras@kvk.uni-neumann.hu
} 
The aim of the study is to determine the effect of abrasion peeling of same amounts of raw material (50 kg of potatoes) on the final product, on the water consumption and on the efficiency of the peeling machine at different operating times.

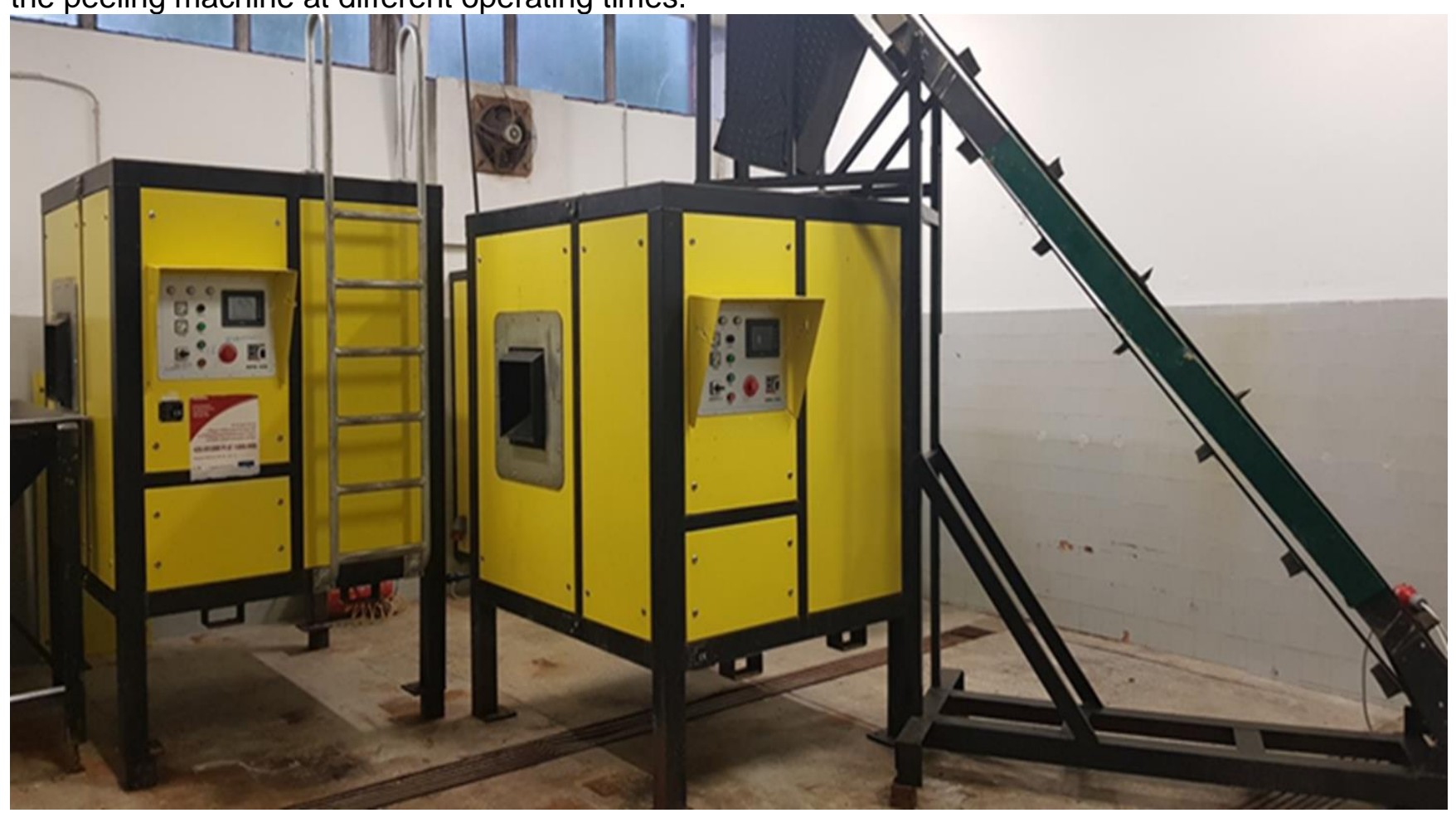

Figure 1. "ROPAI 1000" abrasive peeling machine

\section{Results}

Results can be seen on Table 1. and Figure 2.

Table 1. Results demonstrate that abrasive peel loss highly depends on the operating time

\begin{tabular}{|l|l|l|l|l|}
\hline & & \multicolumn{3}{|c|}{ Operating times } \\
\hline Variety & Raw material kg & 1 min 29sec & $58 \mathrm{sec}$ & $33 \mathrm{sec}$ \\
\hline & & Peel loss (\%) & \\
\hline Desiree & 50 & $48,32 \%$ & $24,16 \%$ & $10,76 \%$ \\
\hline & & Machine performance (\%) \\
\hline Desiree & 50 & $51,68 \%$ & $75,84 \%$ & $89,34 \%$ \\
\hline & & Water consumption (liter) \\
\hline Desiree & 50 & 36 & 18 & 14 \\
\hline & & Permeability (tons) \\
\hline Desiree & 50 & 1,054 & 2,625 & 4,864 \\
\hline
\end{tabular}




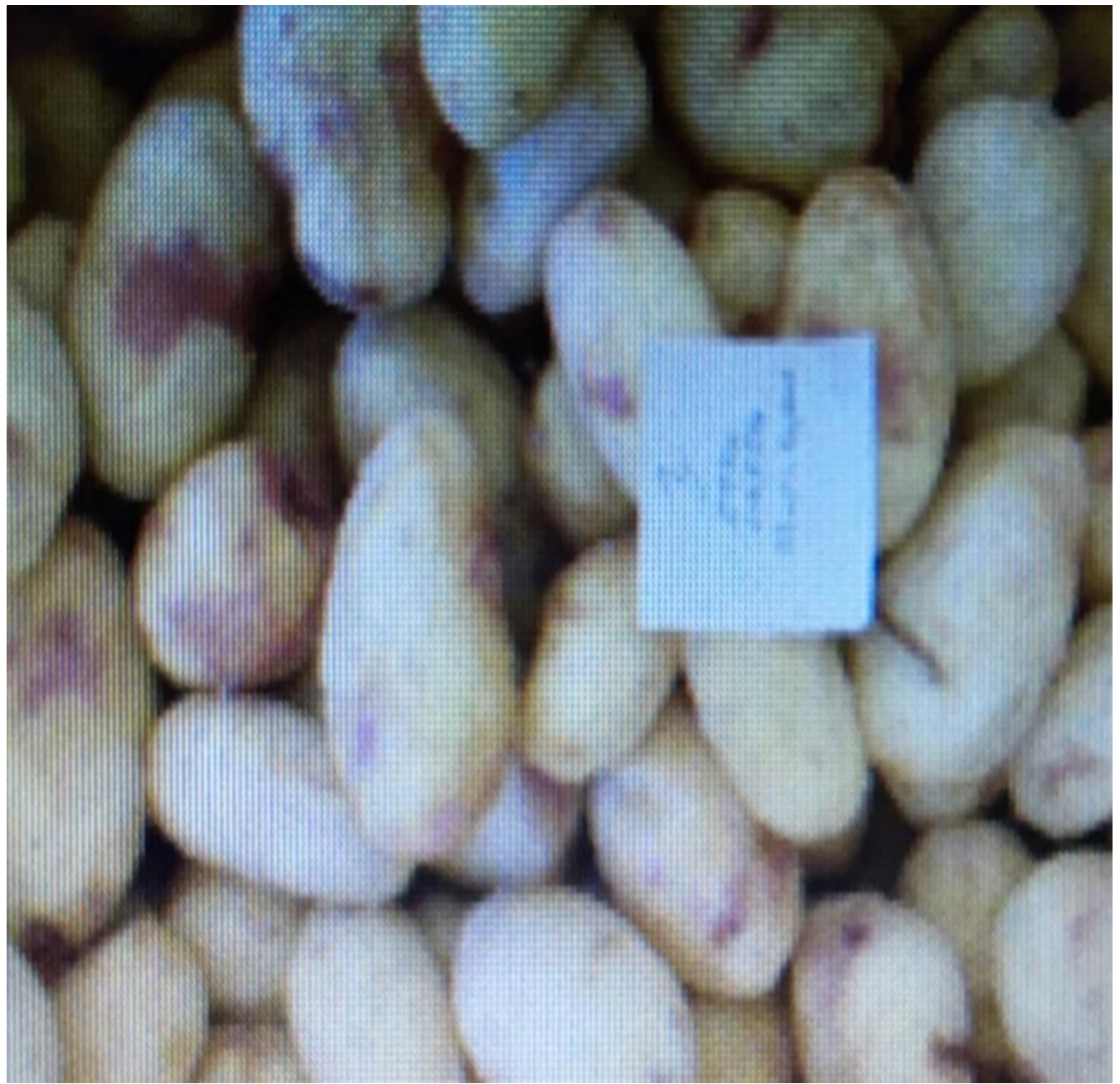

Figure 2. Desiree potato after 52 seconds abrasive peeling

\section{Conclusions}

We can conclude that through the right variety choice and product origin, the well-calculated operating time and its precise and continuous maintenance is essential for the economical operation of a vegetable processing plant. However, this continuous, tight schedule of technology can only be achieved with a professional automation system, so incorporating a computer-driven technological development is a good investment in a traditional vegetable processing plant. Against this background, the automation of a vegetable processing plant is only successful if we are aware of the processing characteristics of the types of vegetables to be processed. Therefore, it is very important to carry out proper studies and agricultural research before starting such an investment.

The optimal operating time for Desiree potato is 52 seconds. Technological time cannot be reduced to the extremes, because at some point, manual knife peeling after abrasion entails higher labor costs than machine peeling for a few more seconds and thus more loss.

\section{Acknowledgement}

We are grateful for the support of the research that carried out in the framework of the EFOP3.6.2-16-2017-00012 "Developing functional, healthy and safe food product chain model from field to table in a thematic research network" at John von Neumann University. The project is funded by the Hungarian State and the European Union, co-financed by the European Social Fund, and is part of the Széchenyi 2020 program. 


\section{References}

[1] Processing, packaging solutions. [Online]. Available: https://proexfood.com/product/fruit-vegetable-packagingequipment/

[2] Automation in the food industry. [Online]. Available: https://www.foodprocessing.com/articles/2018/automation-inthe-food-industry 